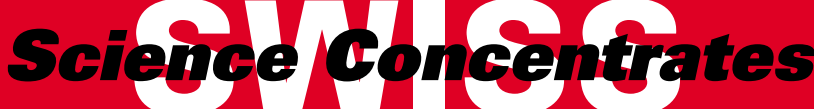

\section{Structural Basis of Thiamine Pyrophosphate Analogues Binding to the Eukaryotic Riboswitch}

S. Thore, C. Frick, and N. Ban*, J. Am. Chem. Soc. 2008, 130, 8116 ETH Zurich

Previously, it was shown that pyrithiamine pyrophosphate (PTPP) has an antibiotic effect thanks to an interaction with the thiamine pyrophosphate (TPP)-specific riboswitch. In this article, the authors report the structure of the eukaryotic TPP-sensing riboswitch in complex with oxythiamine pyrophosphate (OTPP) and PTPP. The crystal structure provides detailed chemical information and allows a better understanding of the interactions between PTPP and TPP-specific riboswitch. This observation has implications for the design of novel antimicrobials targeting TPP-sensing riboswitches.

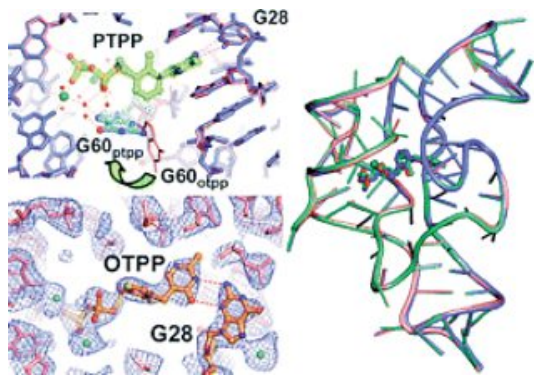

\section{Gas-Phase Synthesis and Reactivity of a Gold Carbene Complex}

A. Fedorov, M.-E. Moret, and P. Chen*, J. Am. Chem. Soc. 2008, 130,8880

ETH Zürich

In this article, the first example of the mass spectrometric characterization of a benzylidene gold carbene is reported. The complex, with a supporting NHC ligand, corresponds to a type of reactive intermediates which have been presumed to act in gold-catalyzed cyclopropanation reactions, but which have not been observed to date in solution- or gas-phase experiments. The nature of the synthesized carbene is clearly demonstrated by its characteristic gasphase chemical reactivity with olefins, including cross-metathesis and cyclopropanation reactions.

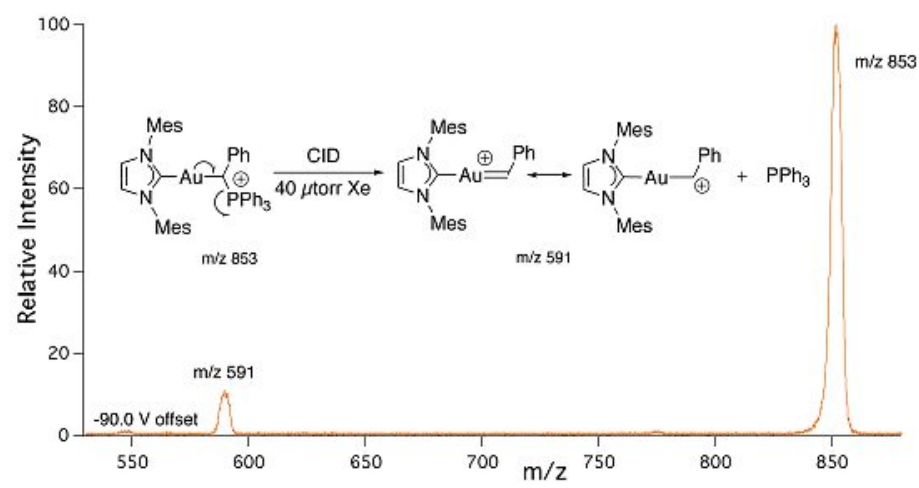

\section{Nickel Complexes of a Pincer $\mathbf{N N}_{2}$ Ligand: Multiple Carbon-Chloride Activation of $\mathrm{CH}_{2} \mathrm{Cl}_{2}$ and $\mathrm{CHCl}_{3}$ Leads to Selective Carbon-Carbon Bond Formation}

Z. Csok, O. Vechorkin, S. B. Harkins, R. Scopelliti, and X. Hu*, J. Am. Chem. Soc. 2008, 130, 8156

EPF Lausanne

This article presents the development of a new pincer-type amido bis(amine) ligand, named $\mathrm{NN}_{2}$, and its transformation into lithium and nickel complex. The $\mathrm{Ni}$ (II) alkyl complexes react cleanly with alkyl halides including chlorides to form $\mathrm{C}-\mathrm{C}$ coupled products and $\mathrm{Ni}$ (II) halides. The $\mathrm{Ni}$ (II) alkyls undergo also reactions with $\mathrm{CH}_{2} \mathrm{Cl}_{2}$ and $\mathrm{CHCl}_{3}$ to cleave all the $\mathrm{C}-\mathrm{Cl}$ bonds and replace them with $\mathrm{C}-\mathrm{C}$ bonds. The reactions are highly selective and lead to efficient catalytic couplings of $\mathrm{CH}_{2} \mathrm{Cl}_{2}$ with alkyl Grignards.

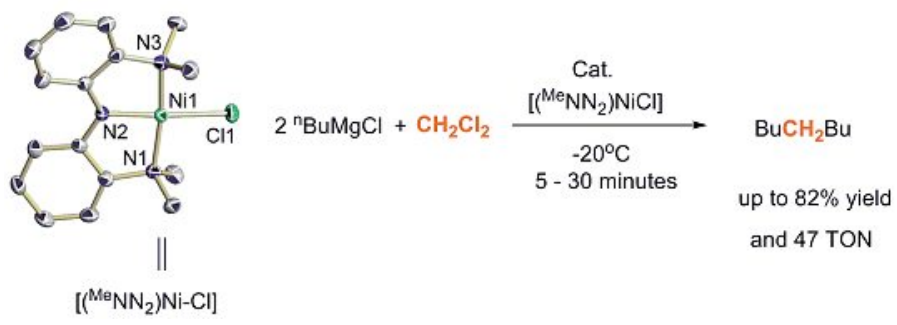

\section{Real-time Monitoring of a Dynamic Molecular System Using ${ }^{1} \mathrm{H}-{ }^{13} \mathrm{C}$ HSQC NMR Spectroscopy with an Optimized ${ }^{13} \mathrm{C}$ Window}

G. Gasparini, B. Vitorge, P. Scrimin, D. Jeannerat, * and L. J. Prins* Chem. Commun. 2008, 3034

CNR ITM \& University of Padova; University of Geneva

NMR spectroscopy is a powerful tool for monitoring the network composition and the reaction pathways of complex mixtures of molecules. In this article, a complex system consisting of four hydrazones and the corresponding four hydrazides is used as model of study. The authors show that the kinetic and thermodynamic parameters of the equilibrating network of the eight molecules can be determined from a series of quick and highly resolved ${ }^{1} \mathrm{H}-{ }^{13} \mathrm{C}$ HSQC NMR experiments obtained using a reduced carbon spectral window.

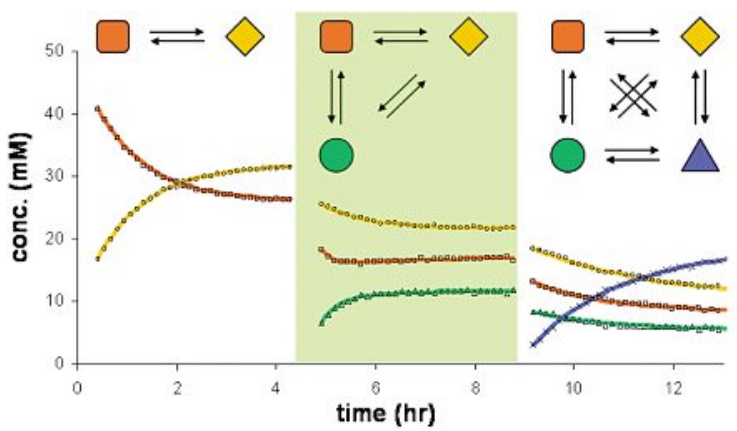

Prepared by Martina Austeri, Renaud Bach, Nathalie Mehanna, Roman Novikov, Ankit Sharma, Franck Torricelli, Jérôme Lacour Do you want your article to appear in this SWISS SCIENCE CONCENTRATES highlight?

Please contact concentrates@chimia.ch 